\title{
Telas rectangulares decoradas: Piezas de vestimenta del Período Tardío Preincaico (San Juan, Argentina)
}

\section{RESUMEN}

Se describen y caracterizan ciertas piezas textiles que forman parte de conjuntos funerarios del Período Tardío Preincaico de los valles de Iglesia y Calingasta (provincia de San Juan, Argentina). Se analizan los contextos culturales que integran junto con prendas de mayor tamaño como ponchos y camisetas.

Palabras claves: telas rectangulares - conjuntos funerarios - Período Tardio Preincaico - San Juan (Argentina).

\section{ABSTRACT}

Certain textile pieces that are part of funeral assemblies of the Late Pre-Inca Period of Iglesia and Calingasta valleys (province of San Juan, Argentina) are described and characterized. An analysis is carried out of the cultural contexts they form part of, with larger size items, like ponchos and shirts.

Key words: rectangular fabrics - funeral assemblies - PreInca Late Period - San Juan (Argentina).

\section{Introducción}

La zona de los valles preandinos de Iglesia y Calingasta en la provincia de San Juan, Argentina, ha provisto de excepcionales materiales arqueológicos durante años. Sus características ambientales particulares permitieron la conservación de elementos perecederos de prácticamente todas las etapas de poblamiento prehispánico. En particular, y para los últimos momentos, se destaca en los mismos la conservación de textiles.

Desde hace casi cuarenta años existen en la provincia trabajos arqueológicos sistemáticos y organizados a través del programa "Conocimiento y difusión de la prehistoria de San Juan” del Instituto de Investigaciones Arqueológicas y Museo "Prof. Mariano Gambier" de la Universidad Na-

\footnotetext{
1 Instituto de Investigaciones Arqueológicas y Museo "Prof. Mariano Gambier", FFHA, Universidad Nacional de San Juan (Argentina). Email: ctmg51@infovia.com.ar
}

cional de San Juan. A pesar de ello, durante mucho tiempo, e incluso en forma simultánea, estas zonas han sido objeto de expoliaciones por parte de coleccionistas y falsos arqueólogos, mientras que algunos hallazgos ocasionales pasaron a integrar colecciones de museos nacionales o internacionales.

Algunos de estos antiguos hallazgos ocasionales fueron conocidos en su momento por la intervención de arqueólogos de reconocida trayectoria (Debenedetti 1915: 50-73, Vignati 1934, Constanzó s.f.) mientras que el desconocimiento de su contexto geográfico, cronológico y cultural ha motivado algunas recientes interpretaciones, a nuestro juicio, incorrectas de los mismos (Renard 1994a, 1994b 1997: 296-303, Dransart 2000: 129-130).

A partir de las excavaciones arqueológicas realizadas entre 1986 y 1999 por Mariano Gambier en Calingasta e Iglesia se obtuvieron elementos textiles provenientes de sitios de habitación y de tumbas; su estudio está permitiendo una más acabada comprensión de sus características y de su utilización como artículos de uso diario y piezas de vestimenta, y como integrantes de ajuares funerarios. Por otra parte, el mejor conocimiento de los elementos y sus conjuntos ha permitido integrar a éstos, otros restos textiles que provienen de hallazgos ocasionales depositados en el mismo Instituto, que se encuentran en colecciones particulares, o que fueron rescatados de las manos de lugareños que buscan objetos arqueológicos para su venta.

Como resultado de estas acciones se han publicado algunos trabajos parciales (Michieli 1986, 1994, 2001a, 2001b, 2002). Resta aún analizar en detalle varias prendas de los fardos funerarios que, por su cantidad, son estudiados por etapas, mientras se están realizando estudios complementarios, como es la determinación de sexo por $\mathrm{ADN}^{2}$ para

\footnotetext{
2 En colaboración con el Biotechnology Learning Center (Biology Department, Suffolk Community College, Selden, New York).
} 
la correcta identificación de los ajuares. En esta oportunidad se presenta un nuevo avance en las investigaciones.

\section{El marco geográfico, cronológico y cultural}

El desarrollo del Período Tardío Preincaico se ha estudiado principalmente en los valles preandinos de Iglesia y Calingasta. Estos son dos valles longitudinales sucesivos en la zona occidental del territorio provincial extendidos a lo largo de una franja entre los 69 $9^{\circ}$ ' y $69^{\circ} 30^{\prime}$ de Long. Oeste y desde los $30^{\circ}$ a $30^{\circ} 30^{\prime}$ y $31^{\circ} 10^{\prime}$ a $31^{\circ} 40^{\prime}$ de Lat. Sur, respectivamente. Están limitados hacia el oeste por los cordones de la Cordillera Frontal y por la Cordillera del Límite (divisoria con la República de Chile) que constituyen la Cordillera de los Andes y por el gran sistema orográfico conocido como Precordillera de La Rioja, San Juan y Mendoza, hacia el este (Gambier 2000: 13-16).

Las zonas más bajas de ambos valles poseen un régimen de precipitaciones por debajo de $35 \mathrm{~mm}$ anuales de promedio, por lo que la vida en ellas es posible necesariamente con el aprovechamiento de los manantiales y cursos de agua que tienen sus orígenes en las nevadas de la zona cordillerana. Esto mismo ha permitido la excelente conservación de los restos de todas las etapas de poblamiento prehispánico (Gambier 2000: 8-11).

La etapa de poblamiento agropecuario tardía de los valles preandinos de Iglesia y Calingasta se desarrolló entre los años 1100 y 1490 DC, antes de la llegada a la región de la conquista incaica. A diferencia de las etapas anteriores, sus características más generales fueron el énfasis en la explotación agrícola y ganadera por sobre las actividades de caza y recolección, que sin embargo no desaparecieron, y el aprovechamiento de los grandes ríos colectores por medio de importantes obras de regadío más que de manantiales y arroyos menores (Gambier 2002).

Si bien participan de ciertos aspectos comunes, en cada uno de los valles se desarrollaron entidades culturales diferentes. En el valle de Calingasta continuó la cultura homónima, luego que se abandonaran las influencias de La Aguada hacia el año 1050 DC. En el valle de Iglesia, con extensión hacia el este a los valles de Jáchal y Bermejo superior, estuvo vigente la conocida cultura de Angualasto, cuyo desarrollo ha podido ubicarse con seguridad entre los años 1200 y 1460 DC según una serie de fechados realizados a partir de las investigaciones recientes (Gambier 2002).

En el valle de Calingasta los estudios se centraron especialmente en el yacimiento de Cerro Calvario, donde se pusieron a la luz restos de viviendas, consistentes en habitaciones rectangulares con muros de tapia, patios y corrales vinculados, canales y acequias. Se hallaron también, dentro de estas instalaciones, dos tipos de tumbas: de pozo y de pozo y cámara; la primera consiste en una fosa elíptica de poca profundidad cubierta por una gruesa capa de sedimentos, mientras que la otra tiene un pozo vertical de hasta un metro de profundidad a partir del cual se abre una cámara a su costado separada del pozo por una estera. ${ }^{3}$ Tanto uno como otro tipo de inhumación contienen un cadáver colocado de cúbito lateral, con las piernas encogidas, las manos sobre la zona ventral y la cara hacia abajo y un ajuar en que se incluyen prendas de vestimenta que lo envuelven prendidas con espinas de algarrobo a modo de alfileres y atados con cordeles diversos, cestos en espiral, recipientes de calabaza (algunos pirograbados), una vasija mediana de cerámica utilitaria y un palo cavador $^{4}$ (Gambier 1994: 15-18 y 2002).

El estudio de las manifestaciones de la cultura de Angualasto en el valle de Iglesia ha permitido su caracterización preliminar en forma más ajustada de lo que tradicionalmente se conocía. Correspondía a una sociedad dedicada especialmente a la agricultura y ganadería intensivas, de organización bastante igualitaria y diferenciación de grupos según la dedicación a una de las dos actividades económicas básicas: la producción agrícola y la cría de animales para el transporte comercial.

Para la agricultura utilizaba las aguas de las grandes corrientes hídricas con un extenso y complejo sistema hidráulico. Las actividades comerciales unieron estos grupos con zonas del Noroeste argentino y Norte de Chile, de las cuales impor-

\footnotetext{
Similar a estas tumbas de pozo y cámara parece ser uno de los tipos de tumbas con alfarería Gentilar que corresponden al Período Intermedio Tardío de Arica (900 a 1450 DC) identificado como "tumbas circulares o cilíndricas con apéndices y subapéndices" (Soto-Heim 1987: 149 y 194) mientras que también se citan "tumbas cilíndricas" para ese mismo período en Quillagua (Agüero y otros 1997: 268).

4 Semejantes a los que se conocen en Chile actualmente con el nombre de tejnes e históricamente con el nombre de chopes.
} 
taron productos suntuarios tales como malaquita para realizar mosaicos, obras de metalurgia, tabletas para alucinógenos y cerámica diaguita chilena y Copiapó, que se encuentran ocasionalmente en las tumbas asociadas con la clásica cerámica Angualasto.

Las instalaciones de esta cultura incluían viviendas de materiales deleznables a lo largo del sistema hidráulico para la población agrícola, y habitaciones y grandes corrales realizados con adobes sobre la superficie del terreno y habitaciones semisubterráneas para la población ganadera. Estas últimas se encuentran agrupadas en grandes núcleos, como la aldea de la localidad que le da el nombre, o en pequeñas agrupaciones a lo largo de las vías de tránsito ligadas con zonas de pasturas (Gambier 1999 y 2000: 55-60).

En todas estas instalaciones, tanto dentro de las viviendas superficiales y semisubterráneas como fuera de ellas, y sin orden ni señalamiento evidente, se encuentran tumbas de pozo y de pozo y cámara para adultos y niños. Los neonatos y nonatos eran enterrados en grandes urnas de cerámica mal cocida, ${ }^{5}$ tapadas con amplias vasijas decoradas de formas abiertas, que se encontraban enterradas en un costado de casi todas las habitaciones. Tanto las tumbas de pozo como las de pozo y cámara contenían un cadáver decúbito lateral con las piernas flexionadas y las manos sobre la zona ventral y con el rostro dirigido hacia el interior o el piso de la tumba. Los ajuares comprendían prendas de vestimenta que envolvían el cadáver prendidas con palitos o cañitas como alfileres y atadas con cordeles y fajas, o que le servían de soporte, cestos en espiral con y sin decoración, recipientes de calabaza (algunos pirograbados), una vasija mediana de cerámica, uno o dos palos cavadores y otros objetos suntuarios y de adorno (Gambier 2002).

\section{Los conjuntos textiles}

\section{Los ajuares de Cerro Calvario (Calingasta)}

a) La tumba de pozo de Cerro Calvario (tumba 1) contenía un fardo (Michieli 2002) formado por

5 También esta forma de enterratorio es semejante a la que acompaña a las tumbas cilíndricas citadas para el Período Intermedio Tardío en Arica y Quillagua (Soto-Heim 1987: 149 y 194, Agüero y otros 1997: 268). una serie de envolturas prendidas con espinas de algarrobo como alfileres y fuertemente atado con cordeles de distinto tipo. Completaban el ajuar restos de cestería en espiral, calabazas pirograbadas y una vasija de cerámica pequeña. La envoltura principal era una camiseta realizada en una tela en faz de urdimbre sin decoración pero con una cadeneta como refuerzo en la base de la abertura para el cuello y costuras decorativas. Estaba realizada con tramas múltiples. Por debajo de esta envoltura se encontraban varios fragmentos de diferente tamaño de otra tela con decoración de listas lisas en sentido de la urdimbre, más oscuras y más claras que el resto del tejido, colocadas a continuación de los orillos laterales. El tercer ejemplar de tejido consistía en grandes restos muy deteriorados de una tela que básicamente fue en faz de urdimbre, muy gastada y sumamente zurcida, con hilos de distinto tipo y grosor que se encontraba sobre el mismo cuerpo. El paquete estaba atado finalmente con una atadura formada por varios tipos de cordeles.

b) En la tumba de pozo y cámara de Cerro Calvario (tumba 2) se halló un fardo funerario (Michieli 2002) correspondiente a un adulto acompañado por recipientes de calabazas pirograbadas y una vasija de cerámica de pequeño tamaño. La envoltura consistía en dos telas prendidas con espinas de algarrobo y atadas con dos tipos de cordeles. La envoltura exterior correspondía a una pieza de vestimenta que debió ser de regular tamaño, aunque ninguno de los fragmentos hallados permitió tomar una medida completa. Por los restos de orillos conservados se pudo establecer, sin lugar a dudas, que se trataba de un poncho de buena calidad por la densidad de la tela y la falta de desgastes y de zurcidos o remiendos. Estaba realizado con una tela en faz de urdimbre sin decoración; los orillos laterales y la abertura para el cuello estaban terminados con un trenzado de cinco elementos elaborado al mismo tiempo del tejido y fijado a los dobleces de la trama simple. En ambos extremos, la abertura para el cuello poseía una cadeneta como refuerzo. Por dentro del paquete y sobre el mismo cuerpo se encontraba una tela basta e irregular, de la cual sólo quedaban fragmentos de regular tamaño. Entre esta tela y el cuerpo, y doblada a lo largo, se encontró una bolsa tejida de color predominantemente rojo. El paquete contenía distintos tipos de cordeles utilizados como ataduras o colocados sueltos. 
Los ajuares de Angualasto (Iglesia)

En Angualasto las tumbas ubicadas dentro del predio de la aldea excepcionalmente conservaban restos textiles; en cambio las localizadas en el sector de Punta del Barro, sobre todo las asociadas con los canales arqueológicos secundarios que se inician allí a partir del canal matriz, contenían fardos funerarios con ofrendas casi intactas en la mayoría de los casos, salvo en las tumbas que habían sido abiertas y su contenido algo removido en fechas no establecidas. En particular se destacan tres tumbas de pozo y cámara con entierros de adultos, dos de pozo con entierros de infantes ubicadas en las inmediaciones del primer canal de Punta del Barro, y una de pozo con entierro de un infante localizada en las inmediaciones del extremo norte del canal matriz.

a) La tumba 1 de pozo y cámara contenía un fardo funerario de un adulto en buen estado de conservación con los siguientes objetos: una camiseta tejida colocada sobre el cuerpo; un cinturón de hilos de lana de camélido en forma de madeja; un par de sandalias de cuero con la suela decorada con grabados; una vincha de hilos de lana de camélido; una envoltura realizada con una excepcional tela rectangular en técnica de faz de trama con decoración multicolor en muy buen estado de conservación, fijada al fardo con ataduras de hilos de lana de camélido; una segunda envoltura realizada con un gran poncho oscuro con refuerzos decorativos, atado a su vez con fajas trenzadas decoradas y una última envoltura realizada con otro gran poncho decorado con urdimbres discontinuas y refuerzos decorativos, también atado con fajas decoradas. Sobre el rostro estaban colocadas dos bolsitas tejidas de forma rectangular, vacías y sin manijas. Por debajo del fardo se ubicaban una camiseta de color claro en buen estado de conservación, otra camiseta en regular estado de color oscuro con refuerzo decorativo y restos de otras dos camisetas - una de ellas también con refuerzo decorativo- muy usadas y reparadas. Dispuestos alrededor del fardo se encontraron una ristra de grandes plumas de ñandú arrollada y atada con un cordel; tres cestos en técnica en espiral decorados; un cesto en técnica encordada roto; un recipiente de calabaza decorado y reparado; un recipiente de calabaza grande sin decoración con vellones de lana de camélido en su interior; un tortero de madera decorado; dos palos cavadores. b) La tumba 2 de pozo y cámara contenía un fardo funerario de un adulto en mal estado de conservación con los siguientes objetos: una camiseta tejida colocada sobre el cuerpo realizada con hilos teñidos de color rojo y refuerzo decorativo; una camiseta de color rojo desleído teñida después de confeccionada con refuerzo decorativo; un poncho; varios trozos de telas viejas; un par de sandalias de cuero con la suela decorada con grabados y pintura de color rojo; varias fajas trenzadas decoradas y cordeles trenzados macizos utilizados como ataduras del fardo; restos de un gorro de red con motas de lana de camélido marrón imitando felpa; restos de cestos.

c) La tumba 3 de pozo y cámara contenía un fardo funerario de un adulto en regular estado de conservación con los siguientes objetos: una camiseta tejida colocada sobre el cuerpo; un cinturón de hilos de lana de camélido con motas de colores en forma de madeja; un par de sandalias de cuero; una vincha de hilos; una envoltura realizada con una camiseta de mediano tamaño decorada con listas verticales y descosida; cordeles de lana de camélido de color beige usados como ataduras; una segunda envoltura realizada con una camiseta descosida; fajas trenzadas decoradas usadas como ataduras; una tercera envoltura realizada con un poncho; varias fajas trenzadas decoradas utilizadas como ataduras exteriores del fardo. El rostro estaba cubierto con dos bolsitas tejidas de forma rectangular, vacías y sin manijas, sostenidas con otra vincha de hilos de lana de camélido. Por debajo del fardo estaban colocados una camiseta de color negro; una camiseta jaspeada; restos de otra camiseta jaspeada; una camiseta de color oscuro en parte rota y restos de otra camiseta de color negro con refuerzo decorativo. Dispuestos alrededor del fardo se encontraron un cesto en espiral decorado; un recipiente de calabaza grande sin decorar; un recipiente de mate cortado en forma de cucharón ("poruña") y una vasija de cerámica tipo Angualasto mediana, de formas simples.

d) Otras dos tumbas de pozo correspondían a entierros de infantes. El primer fardo envolvía el cadáver de un niño de aproximadamente ocho meses de edad que estaba colocado sobre un cesto en espiral de gran tamaño que evidencia desgaste por uso doméstico. El cadáver estaba vestido con un poncho de cuatro orillos de tamaño pequeño y envuelto a su vez con tres telas rectangulares decora- 
das muy gastadas, un pequeño poncho de cuatro orillos muy usado, otro poncho pequeño realizado con un recorte de una pieza mayor deteriorada, una tela de cuatro orillos de tamaño pequeño, fragmentos de otra posible tela rectangular decorada, y de un poncho o camiseta con refuerzo decorativo y restos de telas burdas. El fardo estaba atado con un cordel de $4 \mathrm{~mm}$ de espesor.

e) El segundo fardo contenía el cuerpo de un niño de meses envuelto con los restos de una gastada camiseta de adulto con refuerzo decorativo y una tela rectangular decorada, atados con un cordel de $5 \mathrm{~mm}$ de espesor.

f) La tumba de pozo del extremo norte contenía el cuerpo de un niño pequeño (sin dentición de leche completa) en buen estado de conservación que tenía colocada forzadamente, a modo de faja que sostenía los brazos junto al cuerpo, una camiseta lisa de tamaño pequeño. El fardo contenía también una madeja de hilos de lana de camélido con motas de colores; una envoltura formada por una camiseta de adulto con desgastes por uso; una madeja de hilos de color rojo oscuro de extraordinaria suavidad utilizada como atadura; una segunda envoltura consistente en una camiseta de adulto de color negro con refuerzo decorativo y huella de uso, y varias ataduras externas consistentes en cordeles de lana de camélido de color rojo y de color azul-verdoso.

g) En la aldea, una de las tumbas de pozo ubicada dentro de una vivienda semisubterránea conservaba restos de una tela decorada sobre los pies y la parte inferior de una de la piernas de un esqueleto de adulto.

\section{Características generales}

Los conjuntos textiles provenientes de las tumbas de pozo y de pozo y cámara de ambos valles correspondientes a las manifestaciones del Período Tardío Preincaico de la región, presentan grandes $\mathrm{y}$ fundamentales similitudes.

Son también comparativamente semejantes, individualmente o en conjunto, a otros de la misma pertenencia cultural que, provenientes de hallazgos anteriores (realizados desde principios del siglo XX), ya han sido publicados. Para Calingasta estos son: Quebrada Seca, Río Salado, Hilario, Sorocayense y Cerro Calvario (Michieli 1986,
1994; Corcuera s.f.: 29), Villa Corral (Michieli 2001b: 67-68) y Alto Verde (Debenedetti 1915, Renard 1994a). Para Iglesia son: zona de Angualasto, zona de Cerro Negro, Chinguillos y Las Bóvedas (Michieli 2001a: 44-52) y Buena Esperanza (Vignati 1934, Renard 1994b, Corcuera s.f.: 33).

Entre las similitudes se encuentra en primer lugar la forma de los fardos funerarios de niños y adultos que están constituidos por la envoltura del cadáver por una o varias capas de tejidos, prendidos con espinas, palitos o cañitas a modo de alfileres y fuertemente atados con cordeles o trenzados de hilos. El resto del ajuar textil incluye eventualmente vinchas, sandalias, gorros y cinturones.

Aunque forman parte de ajuares funerarios, casi todos los tejidos son piezas de vestimenta, entre las cuales se destacan ponchos, camisetas y algunas telas rectangulares decoradas con medidas normalizadas para cada caso. Con una sola excepción, las prendas están realizadas con telas de cuatro orillos tejidas con técnica de faz de urdimbre.

Todas las telas están realizadas con hilos de lana de camélido muy delgados y retorcidos en $\mathrm{S}$; a pesar de ello, y en el caso de ponchos y camisetas, el tejido tiene una alta densidad, lo que lo hace compacto y pesado. Generalmente para la decoración se ha utilizado selección de tonos naturales de la lana de camélido (desde beige casi blanco a marrón oscuro casi negro) y, menos comúnmente, hilos teñidos en colores rojo y verde, como es tradicional en las culturas locales, y en forma novedosa en colores amarillo (u ocre) y azul.

La decoración de las telas es en general por listas en sentido de la urdimbre lisas o decoradas con alternancia de urdimbres, urdimbres transpuestas, urdimbres suplementarias y urdimbres suplementarias flotantes. También aparece como recurso de decoración importante en grandes piezas el uso de urdimbres discontinuas ${ }^{6}$ y prendas confeccio-

\footnotetext{
6 Para este caso se documentan hasta ahora cuatro casos semejantes, especialmente de ponchos de gran tamaño, confeccionados con urdimbres discontinuas a la altura de los hombros: Sorocayense y Villa Corral en Calingasta (Michieli 1986: 377, 1994: 24, 2001b: 67-68) y Angualasto (tumba 1) y Buena Esperanza en Iglesia (Michieli 2001a: 64, Vignati 1934, Renard 1994b, Corcuera s.f.: 33).
} 
nadas totalmente con hilos teñidos, o teñidas en forma completa una vez terminadas, en color rojo. ${ }^{7}$ Como excepción aparece un caso de tejido en faz de trama o tapiz multicolor y un tejido en faz de urdimbre con una lista decorativa realizada con tramas suplementarias de cuatro colores.

Las piezas presentan similares costuras decorativas de terminación y de unión y, en el caso de las aberturas para el cuello de ponchos y camisetas que están realizada con urdimbres discontinuas en la parte central de las telas, existen refuerzos en cada uno de los extremos. Los orillos de las telas son también similares, destacándose el uso de costuras en punto de aguja o cadenetas para cubrir los extremos de urdimbres (que en el caso de ponchos y camisetas constituyen el ruedo de la prenda) y de acordonados o trenzados en los orillos laterales. Estas terminaciones consisten en grupos de hilos que se entrelazan alternadamente con los dobleces de trama; en estos casos la trama utilizada en el tejido es simple. En algunos pocos casos se utilizaron tramas múltiples.

La mayoría de las piezas que forman estos fardos, incluso las decoradas, tienen evidencia de uso prolongado que ha ocasionado desgastes, remiendos y zurcidos varios, lo que indica que las mismas no fueron realizadas exclusivamente como prendas funerarias. En varios casos, los restos de estas telas han sido usados como trapos para rellenar o sostener los fardos.

Las diferencias que se advierten entre los textiles de Iglesia y de Calingasta son de detalles y están relacionados con una mayor riqueza en el caso de los pertenecientes a la cultura de Angualasto (Iglesia) que se evidencia en una mayor cantidad de prendas y objetos de ajuar en los fardos funerarios y por la presencia de recursos técnicos especiales para la decoración de telas y de objetos relacionados de tipo suntuario.

Particularmente estas diferencias son: a) piezas de vestimenta de tamaño infantil en Angualasto; b) presencia más usual de sandalias, con y sin decoración, en los fardos de Angualasto; c) presencia

\footnotetext{
Para este caso se documentan dos camisetas de la tumba 2 de Angualasto en Iglesia (Michieli 2001b: 65) y un gran poncho de Sorocayense en Calingasta (Michieli 1994: 24) reproducido por Corcuera (s.f.: 29).
}

eventual de gorros en Angualasto; d) uso de fajas trenzadas decoradas en Angualasto; e) utilización excepcional de técnica y decoración en faz de trama en Angualasto; f) empleo de las terminaciones de orillos laterales con acordonado y trenzado en forma más usual en Angualasto y de tramas múltiples en Calingasta; g) utilización en Angualasto del teñido de hilos de lana en colores azul y amarillo, además de los tradicionales rojo y verde; h) decoración de hilos y cordeles por teñido con reserva en Angualasto; i) refuerzos decorativos para las bases de las aberturas para el cuello en ponchos y camisetas de Angualasto, realizados con tramas suplementarias (a veces flotantes) de hilos teñidos.

Aproximadamente la mitad de los ponchos y camisetas de Angualasto presenta refuerzos decorativos en los extremos de la abertura para el cuello realizados con técnica de faz de trama en el mismo momento del tejido. Estos refuerzos están confeccionados con hilos de lana de camélido de color rojo teñido, verde teñido y beige o marrón natural formando motivos que incluyen combinaciones de espirales curvas o cuadrangulares, líneas oblicuas y triángulos escalerados; sucesión de chevrones, o sucesión alternada de espirales que nacen de un tronco común y que forman con el fondo figuras de tipo complementario. Los motivos de estos refuerzos decorativos, que se repiten en algunas de las decoraciones de telas con listas en sentido de la urdimbre y en la tela rectangular realizada en faz de trama, han sido interpretados anteriormente como atributos del cóndor macho adulto (Michieli 2001a: 56-61, 2001b: 69).

Para la ubicación cronológica exacta de estos conjuntos se realizaron fechados de radiocarbono en algunas de las tumbas. La tumba de pozo y cámara de Cerro Calvario se fechó a través de los palitos de chilca (Baccharis sp.) que formaban la estera que separaba la cámara del pozo y dio una fecha calibrada de 1180 DC (edad radiocarbónica: $880 \pm 50 \mathrm{AP}$ ), mientras que para las tumbas 2 y 3 de Angualasto (sector Punta del Barro), los análisis fueron realizados sobre uñas del pie y dieron fechas calibradas de 1300 y 1400 DC respectivamente (edades radiocarbónicas: $550 \pm 40$ y $590 \pm$ 40 AP) (Gambier 2002). Teniendo en cuenta que diez fechados calibrados realizados para Angualasto, tanto en tumbas como en construcciones superficiales y semisubterráneas, abarcan un rango temporal que va de 1260 a 1430 DC y 
que las edades radiocarbónicas de éstos y otros fechados anteriores no calibrados abarcan un rango que va de 810 a 510 años AP, puede afirmarse con bastante certeza que los conjuntos textiles correspondientes al desarrollo tardío de Calingasta son algo más antiguos que los semejantes de la cultura de Angualasto.

En cambio, los fechados realizados sobre un conjunto textil similar hallado en forma casual en Lorohuasi (provincia de Catamarca), que se ubican a partir de 1440 DC (Renard 1997: 299), parecen indicar que en el Noroeste argentino este tipo de textiles fueron usuales en tiempos posteriores al desarrollo de Angualasto. Por otra parte, las características definitorias de la textilería tardía local, son diferentes a las que introdujo posteriormente el imperio incaico durante su corto dominio en la región (Michieli 1990).

\section{Las telas rectangulares decoradas}

En todos estos ajuares funerarios fueron identificadas sin dificultad camisetas y ponchos como prendas de vestimenta; las mismas tienen características similares y están realizadas con telas de cuatro orillos con medidas normalizadas para cada caso, que se diferencian a su vez de las telas elaboradas para confeccionar camisetas durante la época incaica (Michieli 2001b: 68-69).

Con la continuidad del análisis del resto de las piezas que conforman estos ajuares y la comparación con otros ya descritos, pudo también observarse la reiterada aparición de ciertas piezas que reúnen características semejantes y que hemos identificado como "telas rectangulares decoradas". En algunos casos estas piezas están completas; en otros casos existen fragmentos que, por sus características, pueden ser identificadas como pertenecientes a objetos similares.

Tela rectangular decorada de la tumba 1 de Cerro Calvario (Calingasta)

Está realizada en técnica de faz de urdimbre con hilo de lana de camélido de color beige oscuro retorcido en S. Existen restos de los orillos: el correspondiente al encabezamiento de urdimbre tiene las tres primeras pasadas de trama con hilo doble; el orillo lateral está realizado con tramas múltiples en número de cuatro o cinco. La decoración de la tela consiste en bandas en sentido de la urdimbre más oscuras y más claras que el resto

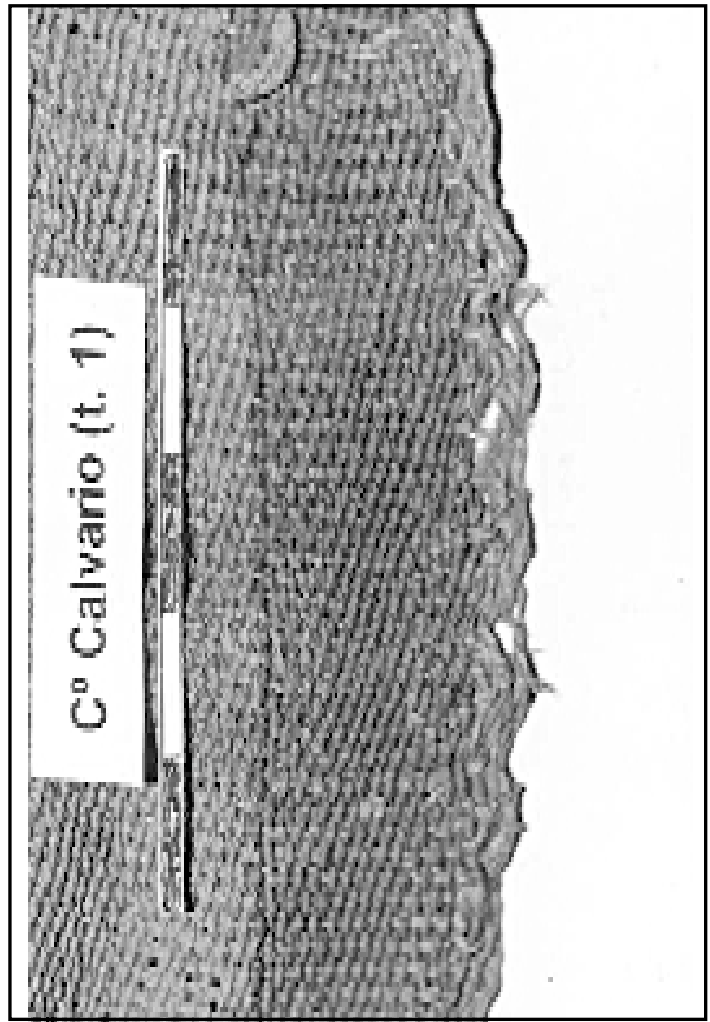

Figura 1. Orillo de tela rectangular decorada con lista lisa en sentido de la urdimbre y uso de tramas múltiples (Calingasta, Cerro Calvario, tumba 1).

del tejido, colocadas a continuación de los orillos laterales (Figura 1). Por sectores el orillo conserva restos de una costura decorativa muy irregular, realizada con punto ojal. Dos fragmentos de esta tela están unidos por sus laterales no decorados con grandes puntadas en punto guante. Toda la apariencia de esta tela, que no presenta desgastes ni zurcidos, y es más fina y liviana que la de la camiseta que la acompañaba, permite suponer que se trataba de una tela rectangular formada por dos paños simétricos unidos por el medio.

Tela rectangular decorada $\left(\mathrm{N}^{\mathrm{o}} 1\right)$ del cadáver infantil colocado en un cesto (Angualasto, sector Punta del Barro

El fardo estaba envuelto con una tela rectangular de cuatro orillos de $130 \mathrm{~cm}$ de largo por $80 \mathrm{~cm}$ de ancho; está realizada en técnica de faz de urdimbre. La urdimbre es un hilo de lana de camélido beige de diferentes tonos, de 2 cabos retorcidos en $\mathrm{S}$ y $0.5 \mathrm{~mm}$ de espesor; la trama es de lana de camélido beige, de 2 cabos retorcidos 


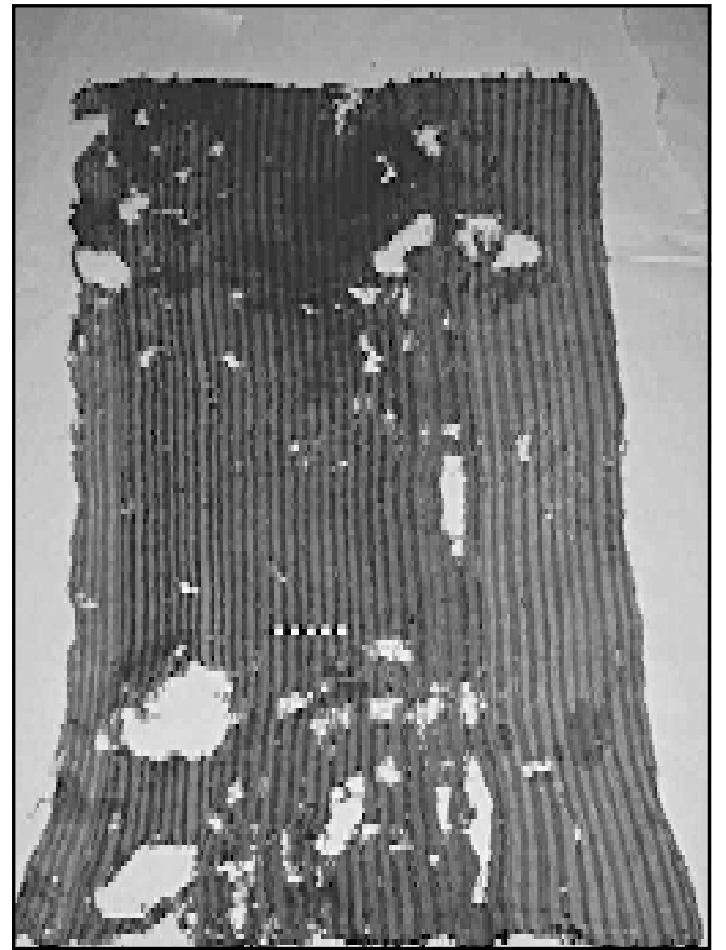

Figura 2. Tela rectangular decorada con listas lisas en sentido de la urdimbre (Angualasto, sector Punta del Barro, niño con cesto).

en $\mathrm{S}$ y $1 \mathrm{~mm}$ de espesor con poca retorsión; en algunos sectores al azar la trama es un hilo similar pero de fibra vegetal. No conserva los orillos laterales sino que están cortados, enroscados y recubiertos, uno con punto festón y otro con punto ojal, realizados groseramente. Los extremos de urdimbre tienen las dos primeras pasadas de trama con hilo doble y restos de una costura en punto de aguja variedad A, que se toma en la segunda pasada de trama, realizada con hilo de pelo humano. La decoración de la tela consiste en una sucesión de listas en sentido de la urdimbre en tres tonos naturales de $1 \mathrm{a} 1.5 \mathrm{~cm}$ de ancho (Figura 2).

Tela rectangular decorada $\left(\mathrm{N}^{\circ} 2\right)$ del cadáver infantil colocado en un cesto (Angualasto, sector Punta del Barro)

Mide $96 \mathrm{~cm}$ de largo y por lo menos $45 \mathrm{~cm}$ de ancho; está realizada en técnica faz de urdimbre. La urdimbre es un hilo de lana de camélido bei- ge, de 2 cabos retorcidos en $\mathrm{S}$ y $1 \mathrm{~mm}$ de espesor y la trama similar, pero de $1.5 \mathrm{~mm}$ de espesor y más suelto. En algunos sectores estos hilos tienen un cabo de fibra vegetal. Sólo conserva un orillo lateral con el doblez de trama simple. Los extremos de urdimbre están formados por el doblez simple de la urdimbre; uno tiene las dos primeras pasadas de trama con hilo doble y el otro una costura en punto de aguja o cadeneta realizado con un cordel de color blanco. La decoración de la tela consiste en dos listas en sentido de la urdimbre $4 \mathrm{~cm}$ de ancho, colocadas a 2.5 $\mathrm{cm}$ de los laterales. Estas listas tienen fondo marrón con dos líneas finas realizadas con urdimbres color beige y cuatro líneas con urdimbres transpuestas que forman tres líneas de rombos, salvo en un sector donde existe una equivocación (Figuras 3 y 4b).

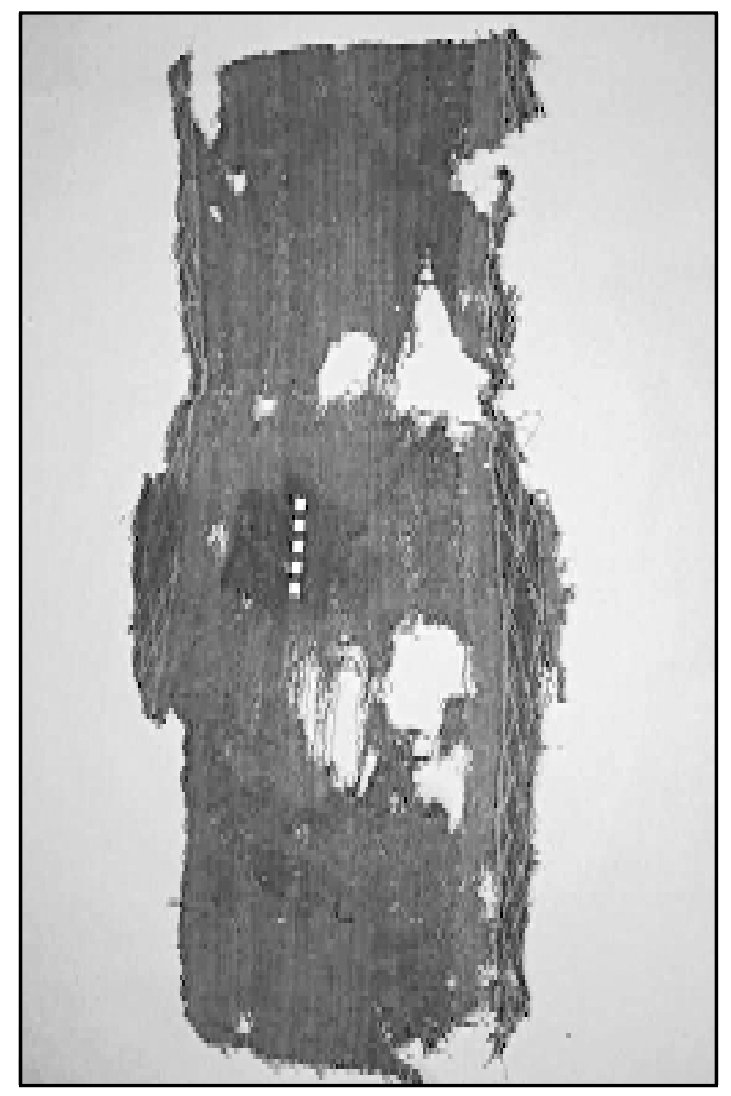

Figura 3. Tela rectangular decorada con listas en sentido de la urdimbre con utilización de urdimbres transpuestas (Angualasto, sector Punta del Barro, niño con cesto). 


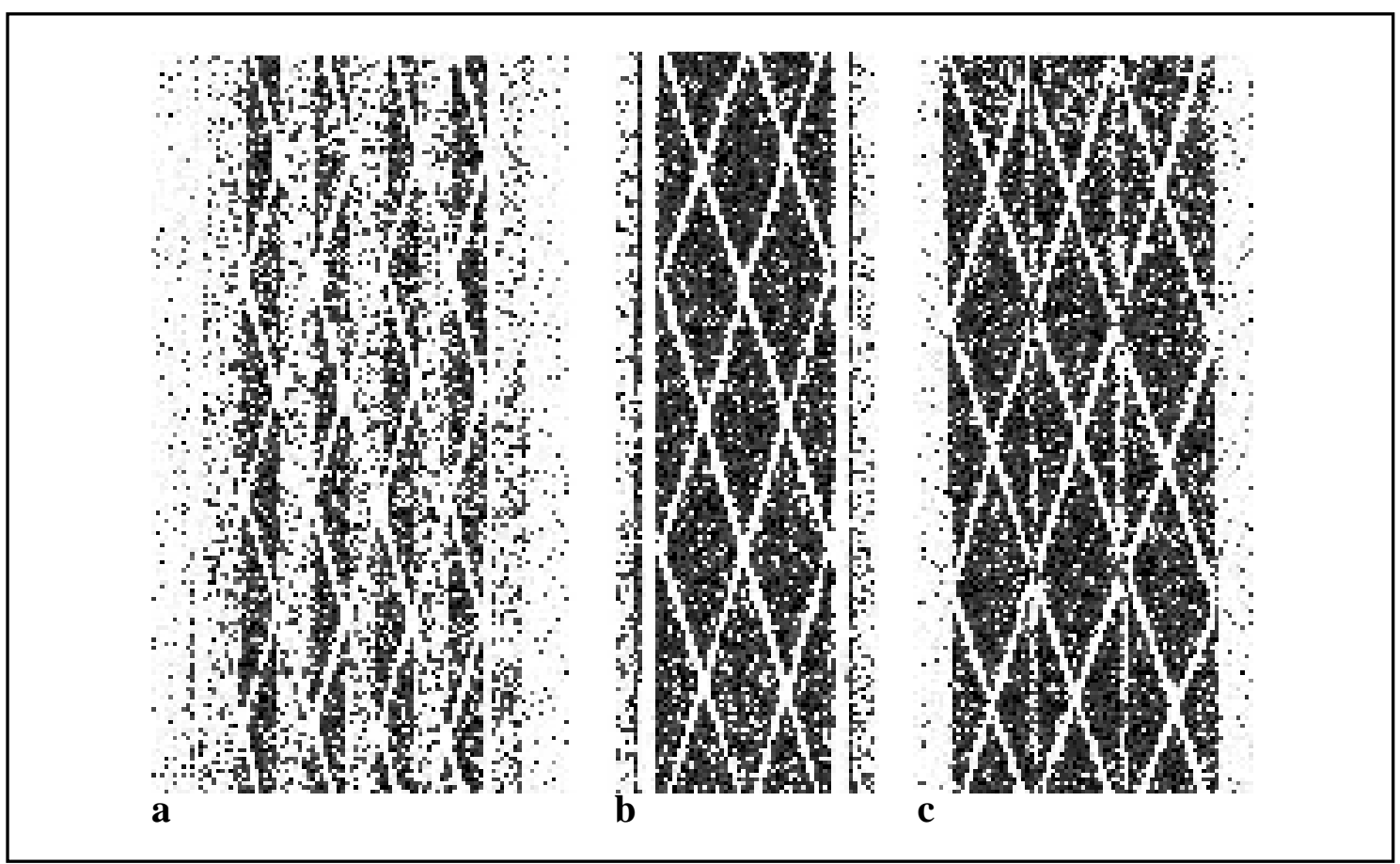

Figura 4. Esquemas de las listas decorativas en sentido de la urdimbre con uso de tramas múltiples: a) Hilario, Calingasta; b) niño con cesto de Angualasto, sector Punta del Barro; c) ejemplar de colección particular, Cerro Negro, Iglesia (dibujos de A. N. Díaz).

Tela rectangular decorada $\left(\mathrm{N}^{\circ} 3\right)$

del cadáver infantil colocado en un cesto

(Angualasto, sector Punta del Barro)

Es una tela rectangular muy rota y zurcida. Tenía por lo menos $130 \mathrm{~cm}$ de largo y más de $57 \mathrm{~cm}$ de ancho. Es una tela en faz de urdimbre decorada con listas en sentido de la urdimbre formadas a su vez por sucesión de rayas en dos tonos de beige (el del fondo y otro más castaño). Algunas tramas tienen un cabo de fibra vegetal.

Tela rectangular decorada del cadáver infantil (Angualasto, sector Punta del Barro)

Tela rectangular decorada, en regular estado de conservación pero que no presenta gastaduras y remiendos. Mide 115 x $60 \mathrm{~cm}$ y está realizada con técnica en faz de urdimbre. La urdimbre es hilo de lana de camélido de 2 cabos, retorcidos en $\mathrm{S}$, de 1 a $1.5 \mathrm{~mm}$ de espesor de diferentes tonos de beige o moliné en dos tonos de beige; el hilo de trama es similar pero de $1.5 \mathrm{~mm}$ de espesor y más suelto. Conserva los cuatro orillos; los menores, correspondientes a los extremos de urdimbre, están formados por los dobleces simples de la urdimbre con costura decorativa en punto de aguja o cadeneta con puntadas desiguales. Los orillos más largos son los laterales y están formados por los dobleces simples de trama sobre los que se fija un acordonado de hilo similar a la urdimbre tomado doble, con un tono contrastante a las primeras urdimbres. La tela está decorada con listas en sentido de la urdimbre de diferente grosor en las orillas (2 a $2.5 \mathrm{~cm}$ ) y después una banda de aproximadamente 2 a $2.5 \mathrm{~cm}$ con fondo beige oscuro y damero en beige claro (Figura 5). Entre estas dos bandas extremas, todo el centro está formado por sucesión de listas finas en diferentes tonos de beige logradas tanto por el cambio de urdimbre como por el uso de hilos moliné en dos todos de beige.

Tela rectangular decorada de la tumba 1 de pozo y cámara

(Angualasto, sector Punta del Barro)

Consiste en una tela rectangular de $120 \times 100 \mathrm{~cm}$ (más ancha que larga), en muy buen estado de conservación, salvo los laterales de trama que se presentan alterados por los fluidos corporales; estos sectores estaban colocados hacia adelante del 


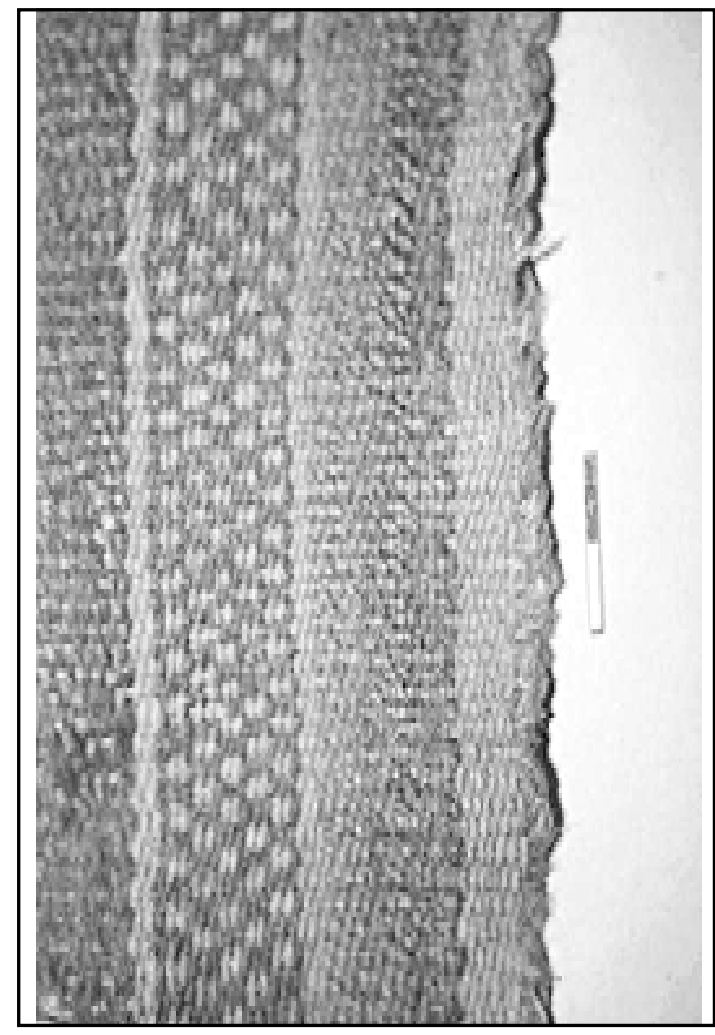

Figura 5. Orillo de tela rectangular decorada con listas en sentido de la urdimbre y terminación con acordonado (Angualasto, sector Punta del Barro, niño sin cesto).

cuerpo mientras que el sector central, mejor conservado, cubría la espalda. Está realizada en técnica de faz de trama (tapiz). La urdimbre es un hilo de lana de camélido marrón, de 2 cabos retorcidos en $\mathrm{S}$ y la trama está configurada por diferentes hilos en colores y tonos diversos, de 2 cabos retorcidos en $\mathrm{S}$, de 0.5 a $1 \mathrm{~mm}$ de espesor. Los colores predominantes son rojo, verde, amarillo y azul teñidos en diferentes tonos y beige muy claro y beige castaño natural. Los orillos están recubiertos con costuras decorativas, con la particularidad de que su confección simula que los extremos de urdimbre fueran los laterales y viceversa. Los orillos correspondientes a los encabezamientos de urdimbre están cubiertos por una costura en punto de aguja o cadeneta que toma uno por uno los dobleces de urdimbre con un hilo similar al de trama tomado doble (uno rojo y uno amarillo). Los orillos correspondientes a los dobleces de trama están cubiertos por costura en punto de aguja o cadeneta que toma entre 3 y 5 dobleces de trama. Está realizada con hilo de lana de camélido negra de 6 cabos retorcidos de a pa- res en $\mathrm{S}-\mathrm{Z}$, de $1.5 \mathrm{~mm}$ de espesor muy parejo y retorcido. La decoración consiste en 10 listas en sentido de la trama con zigzagues oblicuos que separan campos triangulares de color rojo o azulverdoso. Estos zigzagues terminan en espirales cuadrangulares que combinan los colores de los fondos y el del zigzag (amarillo o beige claro). Ambas orillas comienzan con dos listas lisas de aproximadamente 1 a $1.5 \mathrm{~cm}$ de ancho de color rojo y beige claro y eventualmente existen otras dos listas lisas (una roja de $3 \mathrm{~cm}$ y una verde de $1.5 \mathrm{~cm}$ ) colocadas entre la segunda y tercera lista decorada y otra verde de $1 \mathrm{~cm}$ de ancho colocada entre la tercera y cuarta lista decorada (Michieli 2001b: 70). Las listas decoradas son irregulares (entre 7 y $12 \mathrm{~cm}$ de ancho). Las tramas son discontinuas y se enlazan cuando cambian de color en forma recta que es en todos los casos que determinan el diseño; los planos triangulares que forman los fondos, en cambio, en ocasiones están divididos oblicuamente con tramas discontinuas no enlazadas sino fijadas directamente a una misma urdimbre. Las puntas de las tramas se ocultan entre el tejido, pero en ocasiones alcanzan a aparecer en la superficie. Todo el tejido es irregular en cuanto a la cantidad de tramas y en cuanto a la organicidad del diseño; lo primero produce abultamientos que hacen que los laterales correspondientes a los dobleces de trama no sean rectos sino ondeados. El diseño reproduce los de los refuerzos decorativos de la base del cuello de ponchos y camisetas que se identifican con atributos del cóndor.

En estos ajuares aparecen también algunos fragmentos de telas livianas con listas decorativas que pueden considerarse parte de este tipo de piezas:

Fragmento de tela decorada $\left(\mathrm{N}^{\mathrm{o}} 4\right)$

del cadáver infantil colocado en un cesto (Angualasto, sector Punta del Barro)

Es un fragmento muy deteriorado por el uso de aproximadamente $65 \times 36 \mathrm{~cm}$ de tela en faz de urdimbre. La urdimbre es un hilo de lana de camélido de 2 cabos retorcidos en $\mathrm{S}$ de $0.5 \mathrm{~mm}$ de espesor y el hilo de trama es similar pero de $1.5 \mathrm{~mm}$ de espesor y retorsión más suelta. Conserva un orillo de extremo de urdimbre con el doblez simple. La decoración de la tela se conseguía con urdimbres suplementarias y flotantes de color negro y rojo que forman una lista en sentido de la urdimbre de más $6 \mathrm{~cm}$ de ancho con la alternancia de listas negras y rojas sobre las que 


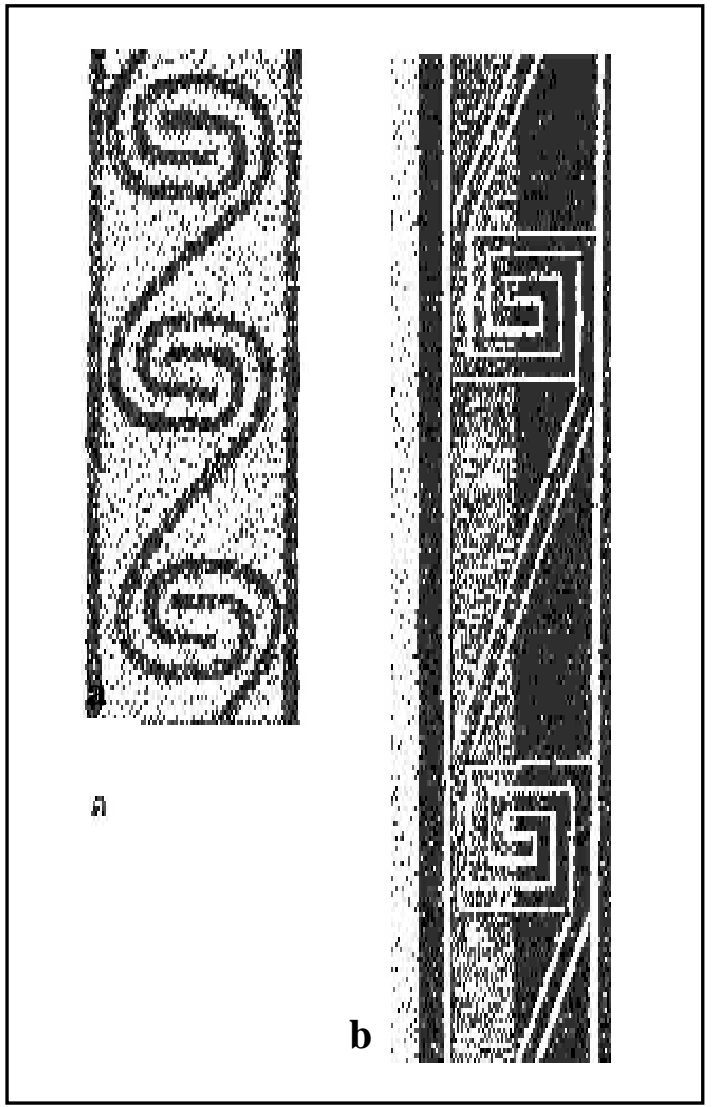

Figura 6. Esquemas de las listas decorativas en sentido de la urdimbre con uso de tramas suplementarias y flotantes: a) camino a Angualasto; b) niño con cesto de Angualasto, sector Punta del Barro (dibujos de A. N. Díaz).

se inscriben dos líneas de espirales cuadrangulares dobles encadenadas; cada una de estas líneas tiene una mitad de cada color (Figura 6b). El motivo reproduce los de la tela en faz de trama y de algunos de los refuerzos decorativos de ponchos y camisetas de Angualasto.

Fragmento de tela decorada de la aldea de Angualasto.

Son tres fragmentos de tela $(29 \times 27 ; 10$ × 9 y 7 x $20 \mathrm{~cm}$ respectivamente; la última tenía el sector decorado) sin restos de bordes que se conservaban sobre los pies y parte de la pierna de un cuerpo de adulto enterrado en una casa semisubterránea de la aldea de Angualasto. Consiste en una tela en técnica de faz de urdimbre. La urdimbre es de hilo de lana marrón oscuro en dos tonos, urdidos alternados, de 2 cabos retorcidos en $\mathrm{S}$ y menos de $1 \mathrm{~mm}$ de espesor; el hilo de trama es similar al de tono más oscuro. Posee una lista decorativa realizada en faz de trama. La decoración (que está en uno de los extremos del trozo con $7 \mathrm{~cm}$ de ancho), es una doble lista realizada con tramas suplementarias discontinuas enlazadas con densidad de 23 tramas por $\mathrm{cm}$, de $4 \mathrm{~cm}$ de ancho total; cada trama, que es un hilo de lana de 2 cabos retorcidos en $\mathrm{S}$, de $0.5 \mathrm{~mm}$ de espesor de colores rojo, verde, beige claro y ocre, toma cuatro urdimbres a la vez y así hace el cambio de densidad. La confección es similar a la de los refuerzos decorativos de ponchos y camisetas. En cada parte de la lista existe un diseño de dos campos en rojo y verde respectivamente que se dividen en forma ondulada por dos pasadas de torcido de trama de color beige en distinta dirección, lo que hace que de un lado se vea como un espigado; en el sector amplio de los campos existe un cuadrado de $9 \mathrm{~mm}$ de lado de color ocre formado por una trama de urdimbre de ancho con el centro formado por dos urdimbres de color contrastante. La reproducción del diseño es especular, pero alterna los colores de los campos, así como el color del centro de los cuadrados, que en una parte son verdes y en la otra, rojos (Figura 7). Este diseño está presente también en objetos de madera y cerámica de Angualasto, combinados con representaciones de atributos del cóndor.

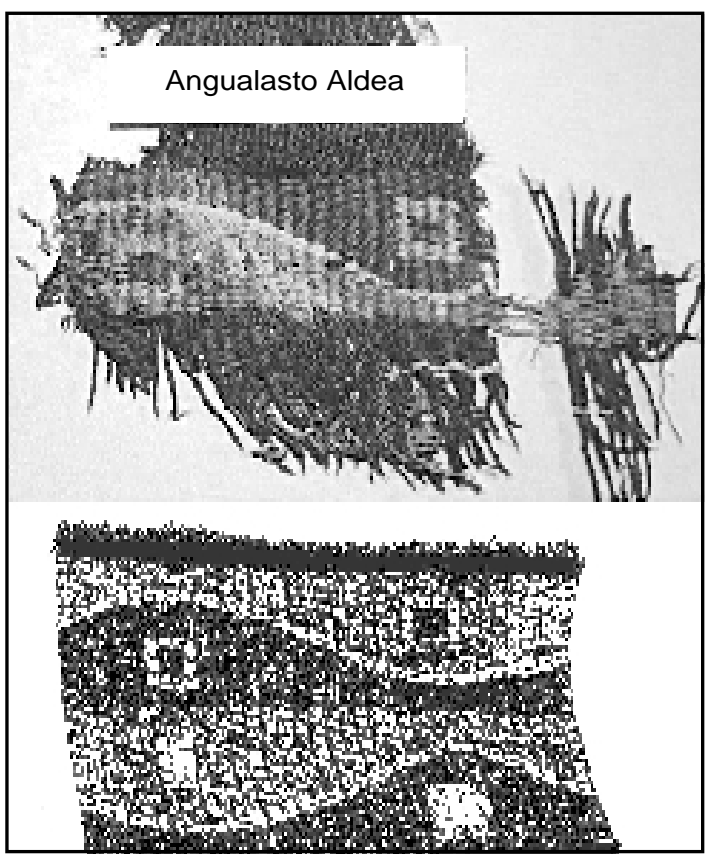

Figura 7. Lista decorativa con utilización de tramas suplementarias discontinuas y enlazadas de la aldea de Angualasto (dibujo de A. N. Díaz). 
En conjuntos semejantes o en hallazgos casuales de ambas zonas, que ya han sido publicados, pueden rastrearse piezas o fragmentos de piezas similares:

Tela rectangular decorada de Hilario (Calingasta)

Se trata de la tela que acompaña un cuerpo hallado en 1941. El lóbulo de la oreja derecha está perforado y atravesado con un grupo de hilos de color rojo que se anudan más abajo. ${ }^{8}$ Tiene decoración de listas en sentido de la urdimbre con utilización de urdimbres transpuestas (Constanzó s.f., Michieli 1994: 12-14) (Figura 4a).

Tela cuadrada decorada de Alto Verde (Calingasta)

La tela, decorada con listas en sentido de la urdimbre, cubría la cabeza del cuerpo conservado hallado a principios del siglo $\mathrm{XX}$ y descrito por Debenedetti (1915: 71-72).

Fragmento de tela decorada de Cerro Negro

Corresponde a uno de los ejemplares de telas pertenecientes a una colección privada que procedería de la margen izquierda del río Blanco-Jáchal, frente a la localidad de Cerro Negro, en el valle de Iglesia. Está decorada con una lista en sentido de la urdimbre con utilización de urdimbres transpuestas (Michieli 2001a: 46) (Figura 4c).

Tela rectangular decorada de Chinguillos

Es uno de los textiles que forman el ajuar de un niño hallado en esa localidad al norte del valle de Iglesia; tiene $84 \mathrm{~cm}$ de ancho y está decorada con listas regulares en sentido de la urdimbre lisas o con dameros en distinto tonos de la lana natural (Michieli 2001a: 49).

Fragmentos de tela decorada del camino a Angualasto

Los restos de una tela decorada envolvían el cadáver de un niño. Estaba decorada con listas en

\footnotetext{
8 En Arica se han encontrado lóbulos perforados atravesados con hilos en cuerpos conservados de épocas preincaicas (Soto-Heim 1987: 192).
}

sentido de la urdimbre; algunas eran lisas y otras tenían motivos de espirales dobles encadenadas, o dameros complejos realizados con utilización de urdimbres suplementarias y flotantes (Michieli 2001a: 51) (Figura 6a).

Fuera de la provincia de San Juan, y en contextos similares, solamente se documenta una pieza algo semejante en Lorohuasi (provincia de Catamarca), de $80 \mathrm{~cm}$ de ancho y $110 \mathrm{~cm}$ de largo y tejida en faz de trama con decoración de listas en sentido de la trama, al parecer realizada con hilados gruesos a juzgar por su descripción como de "importante espesor” (Renard 1997: 300-301).

\section{Conclusiones}

Las características particulares de telas rectangulares decoradas (Cuadro 1) y su reiteración en contextos similares de la etapa tardía de Calingasta y de la cultura de Angualasto en Iglesia permiten su consideración como piezas de por sí, con similares técnicas de confección y decoración y tamaño normalizado.

La mayoría está realizada con técnica de faz de urdimbre y decoración con listas en sentido de la urdimbre. Excepcionalmente existe un ejemplar con decoración por tramas suplementarias y otro realizado enteramente con faz de trama.

Su tamaño oscila entre $0.5 \mathrm{~m}^{2}$ a $1.20 \mathrm{~m}^{2}$ de superficie, aproximadamente. Son piezas medianas y livianas; están confeccionadas con hilos muy finos y con menor densidad de tejido que los ponchos y las camisetas. Si bien la decoración se basa por lo general en listas en sentido de la urdimbre, algunos casos presentan recursos más complicados (urdimbres suplementarias, flotantes y transpuestas) que los usados en las piezas más grandes, lo que posiblemente fuera por la facilidad del trabajo en telas de menor tamaño y más livianas. Lo mismo ocurre con los dos casos que presentan decoración por tramas.

Por los desgastes, roturas, zurcidos y remiendos que presentan, puede considerarse que fueron prendas de uso diario y prolongado antes de integrar ajuares funerarios. Aparecen en contextos de adultos en menor proporción que en los de niños; en estos últimos, a su vez, se observan los ejemplares más deteriorados por el intenso uso. 
TELAS RECTANGULARES DECORADAS: PIEZAS DE VESTIMENTA...

\begin{tabular}{|c|c|c|c|c|c|}
\hline SITIO & $\begin{array}{c}\text { ANCHO en } \mathrm{m} \\
\text { (trama) }\end{array}$ & $\begin{array}{l}\text { LARGO en m } \\
\text { (urdimbre) }\end{array}$ & $\begin{array}{l}\text { SUPERFICIE } \\
\left(\mathrm{en} \mathrm{m}^{2}\right)\end{array}$ & $\begin{array}{l}\text { TECNICA Y } \\
\text { DECORACION }\end{array}$ & CIT. POR \\
\hline Angualasto aldea & - & - & - & $\mathrm{f} / \mathrm{u}$ - tr. supl. discontinuas & \\
\hline Angualasto (niño con cesto) & - & - & - & f/u - u. supl. flotantes & \\
\hline Angualasto (camino) & - & - & - & f/u - u. supl. flotantes & Michieli 2001: 51 \\
\hline Cerro Negro & _- & _- & _ & f/u - u. transpuestas & Michieli 2001: 46 \\
\hline $\mathrm{C}^{\circ}$ Calvario (t. 1) & - & - & - & $\mathrm{f} / \mathrm{u}$ - listas urdimbre & Michieli 2002 \\
\hline Chinguillos & 0.84 & - & - & $\mathrm{f} / \mathrm{u}$ - listas urdimbre & Michieli 2001: 49 \\
\hline Angualasto (niño con cesto) & 0.45 & 0.96 & 0.43 & f/u - u. transpuestas & \\
\hline Alto Verde & 0.70 & 0.70 & 0.49 & $\mathrm{f} / \mathrm{u}$ - listas urdimbre & Debenedetti 1915: 71-72 \\
\hline Angualasto (niño sin cesto) & 0.60 & 1.15 & 0.69 & $\mathrm{f} / \mathrm{u}$ - listas urdimbre & \\
\hline Angualasto (niño con cesto) & 0.57 & 1.30 & 0.74 & $\mathrm{f} / \mathrm{u}$ - listas urdimbre & \\
\hline Hilario & 0.80 & 1.22 & 0.97 & f/u - u. transpuestas & Michieli 1994: 12 \\
\hline Angualasto (niño con cesto) & 0.80 & 1.30 & 1.04 & f/u - listas urdimbre & \\
\hline Angualasto (t. 1) & 1.20 & 1.00 & 1.20 & $\mathrm{f} / \mathrm{tr}$ - tapiz multicolor & Michieli 2001: 66 \\
\hline
\end{tabular}

Cuadro 1. Telas rectangulares decoradas.

La asignación al Período Tardío Preincaico de los valles preandinos de San Juan está avalada por su asociación contextual y temporal que, por otra parte, tiene vinculación con rasgos muy característicos de contextos textiles del norte de Chile considerados de época preincaica.

\section{REFERENCIAS CITADAS}

AGÜERO, C., M. URIBE, P. AYALA y B. CASES, 1997. Variabilidad textil durante el Período Intermedio Tardío en el Valle de Quillagua: Una aproximación a la etnicidad. Estudios Atacameños 14: 263-290, San Pedro de Atacama.

CONSTANZO, M. M., La momia de Calingasta. s.n.t.

CORCUERA, R. s.f. Ponchos de las tierras del Plata. Ed. Verstraeten-Fondo Nacional de las Artes, Buenos Aires.

DEBENEDETTI, S., 1915. Investigaciones arqueológicas en los valles preandinos de la Provincia de San Juan. Revista de la Universidad de Buenos Aires XXXII y XXXIV: 3-184, Buenos Aires.

DRANSART, P., 2000. Vestirse en los períodos tardíos del centro-sur andino. En Actas de la I Jornada Internacional sobre Textiles Precolombinos, V. Solanilla (Ed.), pp. 127-153. Universitat Autònoma de Barcelona, Barcelona.

GAMBIER, M., 1994. La cultura Calingasta. Revista Ansilta 6: 15-18, San Juan.

- 1999. Investigaciones arqueológicas en Angualasto. En Actas del XIII Congreso Nacional de Arqueología Argentina Córdoba 1999, Tomo II. En prensa.

- 2000. Prehistoria de San Juan (segunda edición). Ed. Ansilta, San Juan.
— 2002. Tumbas de "pozo y cámara" con conservación de textiles de la etapa tardía preincaica en una zona andina meridional (San Juan, Argentina). En Actas de las II Jornadas Internacionales sobre Textiles Precolombinos, V. Solanilla (Ed.). Universitat Autònoma de Barcelona, Barcelona. En prensa.

MICHIELI, C. T., 1986. Textilería de la cultura Calingasta (San Juan, Argentina). Comunicación preliminar. Chungara 16-17: 377-380, Arica.

- 1990. Textilería incaica en la provincia de San Juan: Los ajuares de los cerros Mercedario, Toro y Tambillos. Ed. Instituto de Investigaciones Arqueológicas y Museo UNSJ, San Juan.

- 1994. Textilería de la cultura Calingasta. Publicaciones 21: 9-35, San Juan.

- 2001a. Nuevas evidencias textiles del Período Tardío en el valle fronterizo de Iglesia, (San Juan, Argentina) y sus relaciones con el norte de Chile y Noroeste argentino. Publicaciones (nueva serie) 24: 43-62, San Juan.

— 2001b. Textiles de Angualasto: Ratificación de juicios a través de cuatro fardos funerarios. Publicaciones (nueva serie) 24: 63-73, San Juan.

- 2002. Caracterización de los tejidos de la etapa tardía preincaica en una zona andina meridional (San Juan, Argentina). En Actas de las II Jornadas Internacionales so- 
bre Textiles Precolombinos, V. Solanilla (Ed.). Universitat Autònoma de Barcelona, Barcelona. En prensa.

RENARD, S., 1994a. Un textil conservado en el Museo Etnográfico Juan B. Ambrosetti de la Universidad de Buenos Aires y su aporte al conocimiento de técnicas precolombinas. Boletín del Comité Nacional de Conservación Textil 2: 35-40, Santiago.

— 1994b. Vestimenta y jerarquía. Los tejidos de Angualasto del Museo Etnográfico. Una nueva visión. Revista Andina 12(2): 373-401, Lima.
- 1997. Objetos textiles, pasos y caminantes trasandinos. Piezas similares y rasgos comunes en textiles arqueológicos de Argentina y Chile. Estudios Atacameños 14: 291305, San Pedro de Atacama.

SOTO-HEIM, P., 1987. Evolución de deformaciones intencionales, peinados, tocados y prácticas funerarias en la prehistoria de Arica. Chungara 19: 129-213, Arica.

VIGNATI, M. A., 1934. El ajuar de una momia de Angualasto. Notas preliminares del Museo de La Plata, II: 187-231, La Plata. 